\title{
A simple red-ox titrimetric method for the evaluation of photo-catalytic activity of titania based catalysts
}

\author{
Y S SATPUTE, S A BORKAR and S R DHARWADKAR* \\ Department of Chemistry, The Institute of Science, 15, Madam Cama Road, Mumbai 400 032, India
}

MS received 12 August 2003; revised 13 October 2003

\begin{abstract}
A simple red-ox titrimetry method has been developed for rapid evaluation of the photo catalytic activity of $\mathrm{TiO}_{2}$ based photo-catalysts. The analytical procedure employs monitoring the kinetics of a simple one electron transfer reduction reaction of conversion of $\mathrm{Ce}^{4+}$ to $\mathrm{Ce}^{3+}$ in dilute aqueous solution in presence of sunlight. The photo-catalytic activity of $\mathrm{TiO}_{2}$ synthesized by two different routes was evaluated by the above technique. The effect of surface area, crystallite size and polymorphic contents on the photo-catalytic activity of $\mathrm{TiO}_{2}$ was also studied employing this method.
\end{abstract}

Keywords. Red-ox titration; photo-catalysis; titanium dioxide; catalytic activity; synthesis of titania; microwave processing.

\section{Introduction}

Titanium (IV) oxide is the most promising semiconductor photo-catalyst and has been investigated extensively in recent years for wide ranging applications. The diverse applications of this magic material have been covered exhaustively in the reviews recently published (Fox and Dulay 1993; Hagfeldt and Gratzel 1995; Hoffmann et al 1995; Linsebigler et al 1995; Rajeshwar 1996; Fujishima et al 2000) from different reputed laboratories.

The evaluation of catalytic activity of $\mathrm{TiO}_{2}$ used as a photo-catalyst has been frequently made by using sophisticated analytical equipments like GC, HPLC, ICP/MS etc (Okamoto and Yasunori 1985; Dube and Darshane 1993; Prairie et al 1993; Murugesan 2001). These equipments and the chemicals required for the analysis are expensive and beyond the budgetary limits of normal teaching institutions. In the present work, we have developed a simple method for rapid scanning of a large number of $\mathrm{TiO}_{2}$ based photo-catalysts prepared under varying experimental conditions in a relatively short duration in R\&D laboratories having basic analytical facilities. The method suggested here could also be adopted to study the photocatalytic activity of other transition metal oxide based catalysts. For establishing this technique, we have monitored a simple one-electron transfer red-ox reaction involving photochemical reduction of $\mathrm{Ce}^{+4}$ to $\mathrm{Ce}^{+3}$ in dilute ceric sulphate solution. The results presented in this paper show that the technique can be used for rapid scanning of a number of photo-catalyst samples in a reasonably short duration.

*Author for correspondence

\section{Experimental}

\subsection{Preparation of hydroxide precursor}

The $\mathrm{TiO}_{2}$ used in this investigation was prepared from $\mathrm{TiCl}_{4}$ solution (Merck, Synthesis grade with purity, >99\%). Dilute $\mathrm{TiCl}_{4}$ was prepared by controlled addition of concentrated $\mathrm{TiCl}_{4}$ in ice cooled demineralized water. The concentration of $\mathrm{TiCl}_{4}$ in dilute solution was maintained around 2-3 molar. $\mathrm{Ti}(\mathrm{OH})_{4}$ precursors were precipitated from this solution by employing two different processes, viz. (i) controlled precipitation using urea and (ii) hydrolysis of dilute $\mathrm{TiCl}_{4}$ solution.

In controlled precipitation process, dilute $\mathrm{TiCl}_{4}$ solution was mixed with urea in proportion of $\mathrm{TiO}_{2}$ : urea $1: 20$ moles and heated at $\sim 100^{\circ} \mathrm{C}$. The reaction mixture was refluxed for $2-3 \mathrm{~h}$ to ensure completion of the reaction. The precipitate was cooled, filtered and washed several times with hot demineralized water till it was free of chloride ions.

In hydrolysis process, the stock solution of $\mathrm{TiCl}_{4}$ was further diluted five to six times with demineralized water. The solution was refluxed at $100^{\circ} \mathrm{C}$ for $3 \mathrm{~h}$ and cooled to room temperature. Refluxed solution resulted in the formation of a precipitate that settled down on cooling. The supernatant liquid from the slurry was decanted slowly and it was re-mixed with fresh demineralized water. Dilute ammonia was then added to this solution drop wise, under stirring condition till its $\mathrm{pH}$ was neutral $(\mathrm{pH} \cong 7)$. The precipitate so obtained was filtered and washed with demineralized water till free of chloride ions. 


\subsection{Preparation of $\mathrm{TiO}_{2}$ from hydroxide precursor and characterization}

The hydroxide precipitates obtained by both the methods were vacuum dried at room temperature followed by controlled heat treatment at $110^{\circ} \mathrm{C}$ and $300^{\circ} \mathrm{C}$ in microwave system (MW) for $1 \mathrm{~h}$. This resulted in the formation of titanium oxide $\left(\mathrm{TiO}_{2}\right)$, which was characterized by X-ray diffraction technique using $\mathrm{CuK}-\alpha$ radiation (Phillips X'Pert X-ray diffractometer). The crystallite size ' $t$ ' of $\mathrm{TiO}_{2}$ heat treated at different temperatures was evaluated from the half width ' $\mathrm{B}$ ' of the most prominent peak at $50 \%$ intensity using the Debye-Scherrer relation (Cullity 1967) given by

$$
t=\frac{0 \cdot 9 \lambda}{\beta \cos \theta_{\mathrm{B}}},
$$

where $\lambda$ is the wavelength of the radiation $(\AA)$ used and $2 \theta_{\mathrm{B}}$ represents the angle at which the peak is recorded.

The weight fraction of rutile in $\mathrm{TiO}_{2}$ prepared by different methods was calculated using the following equation (Zhang and Banfield 2000)

$$
\alpha=\frac{1}{1+0 \cdot 884\left(A_{\text {anatase }} / A_{\text {rutile }}\right)},
$$

where $A_{\text {anatase }}$ and $A_{\text {rutile }}$ represent respectively the integral intensities of anatase (101) and rutile (110) peaks and $\alpha$ the extent of transformation of anatase i.e. weight fraction of rutile in the mixture.

The surface area of resulting product was measured by BET method employing nitrogen gas adsorption unit (SMART SORB-90) manufactured and supplied by M/s Smart Instrument Co., Dombivali, Maharashtra.

\subsection{Preparation of standard solutions of ceric sulphate and ferrous ammonium sulphate}

A dilute ceric sulphate solution $\left(4 \times 10^{-4} \mathrm{~N}\right)$ was prepared by dissolving the known amount of oven dried $\left(150^{\circ} \mathrm{C}\right.$, $15 \mathrm{~min}$ ) ceric sulphate crystals in $3 \mathrm{~N} \mathrm{H}_{2} \mathrm{SO}_{4}$ solution. The percentage conversion of the $\mathrm{Ce}^{4+}$ to $\mathrm{Ce}^{3+}$ as a function of time was determined by back titrating the residual $\mathrm{Ce}^{4+}$ in solution employing ferrous ammonium sulphate (as a reducing agent) and ferroin as an indicator. The standard ferrous ammonium sulphate solution was prepared by dissolving the freshly re-crystallized ferrous ammonium sulphate in dilute $\mathrm{H}_{2} \mathrm{SO}_{4}$ solution $(3 \mathrm{~N})$.

\subsection{Kinetics of conversion of $\mathrm{Ce}^{4+}$ to $\mathrm{Ce}^{3+}$ in presence of sunlight}

The experiment to study the kinetics of conversion of $\mathrm{Ce}^{4+}$ to $\mathrm{Ce}^{3+}$ in presence of sunlight was performed as follows:

$25 \mathrm{ml}$ of the ceric sulphate solution was taken in $100 \mathrm{ml}$ beaker to which weighed amount of $\mathrm{TiO}_{2}$ powder was added. The amount of $\mathrm{TiO}_{2}$ powder added varied from 25 to $150 \mathrm{mg}$. The ceric sulphate solution containing $\mathrm{TiO}_{2}$ powder was exposed to sunlight and stirred continuously to get uniform dispersion. The solution containing the slurry was exposed to sunlight for different lengths of time and unconverted $\mathrm{Ce}^{4+}$ was estimated by titrating the solution against ferrous ammonium sulphate using ferroin as an indicator. Preliminary results obtained indicated that the amount of $\mathrm{TiO}_{2}$ needed for complete conversion of $\mathrm{Ce}^{4+}$ to $\mathrm{Ce}^{3+}$ contained in $25 \mathrm{ml}$ of solution was about $150 \mathrm{mg}$. In all the subsequent experiments $150 \mathrm{mg}$ of $\mathrm{TiO}_{2}$ was added to $25 \mathrm{ml}$ of the ceric sulphate solution.

For comparison of photo activity of $\mathrm{TiO}_{2}$ prepared by different routes, the experiments were conducted on different samples on the same day at the same time to eliminate any uncertainty resulting from non-identical conditions of the sunlight on different days.

\section{Results and discussion}

\subsection{Physical properties of $\mathrm{TiO}_{2}$ photo-catalysts}

Table 1 summarizes the physical properties such as phase composition and crystallite size derived from X-ray diffraction (XRD), and BET surface area of the powders

\begin{tabular}{|c|c|c|c|c|}
\hline \multirow{4}{*}{$\frac{\text { Process }}{\text { Heat treatment }}$} & \multicolumn{2}{|c|}{ Sample A } & \multicolumn{2}{|c|}{ Sample B } \\
\hline & A-1 & A-2 & B-1 & B-2 \\
\hline & \multicolumn{2}{|c|}{ Controlled precipitation } & \multicolumn{2}{|c|}{ By hydrolysis } \\
\hline & $\begin{array}{c}110^{\circ} \mathrm{C} \text { for } \\
60 \mathrm{~min}(\mathrm{MW})\end{array}$ & $\begin{array}{c}300^{\circ} \mathrm{C} \text { for } \\
60 \mathrm{~min}(\mathrm{MW})\end{array}$ & $\begin{array}{c}110^{\circ} \mathrm{C} \text { for } \\
60 \mathrm{~min}(\mathrm{MW})\end{array}$ & $\begin{array}{c}300^{\circ} \mathrm{C} \text { for } \\
60 \mathrm{~min}(\mathrm{MW})\end{array}$ \\
\hline Phases identified by XRD & Anatase & Anatase & Anatase $(40 \%)+$ rutile $(60 \%)$ & Anatase $(33 \%)+$ rutile $(67 \%)$ \\
\hline Surface area $\left(\mathrm{m}^{2} / \mathrm{g}\right)$ & 198 & 100 & 180 & 82 \\
\hline Crystallite sizes $(\AA)$ & 45 & 118 & $\begin{array}{r}77(\mathrm{a}) \\
110(\mathrm{r})\end{array}$ & $\begin{array}{l}130(\mathrm{a}) \\
132(\mathrm{r})\end{array}$ \\
\hline
\end{tabular}

Table 1. Comparison of powder characteristics of the samples obtained by different methods.

a, anatase; r, rutile. 
obtained employing different experimental conditions. The relative amount of anatase and rutile $(\alpha)$ in the powder obtained by hydrolysis process was calculated from XRD using (2). The calculations indicated that at $110^{\circ} \mathrm{C}$, $\alpha$ was $60 \%$ while at $300^{\circ} \mathrm{C}$ the same increased to $67 \%$. The crystallite size of anatase phase in samples A and B increased with increasing temperature (table 1). The relative increase in the crystallite size in pure anatase was higher than that for the same phase in the mixture. The crystallite size for pure anatase increased from $45 \AA$ at $110^{\circ} \mathrm{C}$ to $118 \AA$ at $300^{\circ} \mathrm{C}$, whereas that for anatase in the mixture it increased from $77 \AA$ at $110^{\circ} \mathrm{C}$ to $130 \AA$ at $300^{\circ} \mathrm{C}$.

The surface area of $\mathrm{TiO}_{2}$ prepared by controlled precipitation method having anatase phase (sample A-1) decreased from $198 \mathrm{~m}^{2} / \mathrm{g}$ to $100 \mathrm{~m}^{2} / \mathrm{g}$ by increasing the heat treatment temperature from $110^{\circ} \mathrm{C}$ to $300^{\circ} \mathrm{C}$ (sample A-2). The mean surface area of the mixture of anatase and rutile obtained by hydrolysis, however, decreased from $180 \mathrm{~m}^{2} / \mathrm{g}$ at $110^{\circ} \mathrm{C}$ to $82 \mathrm{~m}^{2} / \mathrm{g}$ at $300^{\circ} \mathrm{C}$ (table 1 ). The order of magnitude of decrease in the surface area in both powders was almost the same $(\sim 50 \%)$.

\subsection{Photo catalytic reactivity}

The plots depicted in figures $2-5$ indicate the percentage conversion of $\mathrm{Ce}^{4+}$ to $\mathrm{Ce}^{3+}$ as a function of time for the samples obtained by controlled precipitation and by hydrolysis route. Figures 2 and 3 compare the reactivity of anatase phase with the mixture of anatase and rutile obtained under identical experimental conditions at $110^{\circ} \mathrm{C}$ and $300^{\circ} \mathrm{C}$, respectively. Figures 4 and 5 highlight the influence of heat treatment of $\mathrm{TiO}_{2}$ on the resulting kinetics.

All the plots of conversion of $\mathrm{Ce}^{4+}$ to $\mathrm{Ce}^{3+}$ in solution, in presence of $\mathrm{TiO}_{2}$ prepared by different methods (figures 2-5), showed that the percentage of $\mathrm{Ce}^{3+}$ in solution increased continuously with time. The extent of increase was found to depend mainly on the temperature at which the sample was prepared and also on the polymorphic form of $\mathrm{TiO}_{2}$ in the sample. $\mathrm{TiO}_{2}$ prepared by heating $\mathrm{Ti}(\mathrm{OH})_{4}$, obtained by dilution method, to $110^{\circ} \mathrm{C}$ (sample B-1) (figure 1b) contained nearly $60 \%$ rutile phase and was found to be much more reactive compared to the sample obtained from $\mathrm{Ti}(\mathrm{OH})_{4}$ precipitated by urea route and heated to the same temperature $\left(110^{\circ} \mathrm{C}\right)$ (figure 2). This latter sample consisted only of anatase phase (sample A-1) (figure 1a). It is interesting to note that the reactivity of the mixture of anatase and rutile prepared at $110^{\circ} \mathrm{C}$ (sample B-1) is substantially higher compared to that of the single anatase phase (sample A-1) despite the fact that the mean surface area of the mixture is $180 \mathrm{~m}^{2} / \mathrm{g}$ compared to $198 \mathrm{~m}^{2} / \mathrm{g}$ for the single anatase phase prepared also at $110^{\circ} \mathrm{C}$. The oxides obtained from the same hydroxide precursor after heating to $300^{\circ} \mathrm{C}$ in MW for $60 \mathrm{~min}$ however, showed reverse trend in their photocatalytic activity. Sample A-2 consisting of a single anatase phase (figure 1c) showed higher reactivity (figure 3) as compared to the mix phase powder containing nearly $67 \%$ rutile phase (figure 1d) (sample B-2). The mean surface area of the mixture prepared at $300^{\circ} \mathrm{C}$ is $82 \mathrm{~m}^{2} / \mathrm{g}$ compared to $100 \mathrm{~m}^{2} / \mathrm{g}$ for the single anatase phase. The decrease in reactivity of the mixture with increasing temperature could be understood both in terms of the decrease in the mean surface area of the sample as well as the increase in the rutile content of the mixture, which is known to be less reactive compared to the anatase phase (Karakitsou and Verykios 1993; Mihaylov et al 1993; Mills et al 1993a, b; Noda et al 1993; Ohtani and Nishimoto 1993; Martin et al 1994).

The enhanced reactivity of anatase with increasing temperature (figure 4) observed in the present study corroborates with the results of previous investigators (Nishimoto et al 1985; Mills and Morris 1993; Mills et al 1993a; Tanaka et al 1993). Mills and Morris (1993) attributed this increase to the increase in mean crystallite size of the phase with increasing temperature. Our results also show a similar trend in the values of the mean crystallite

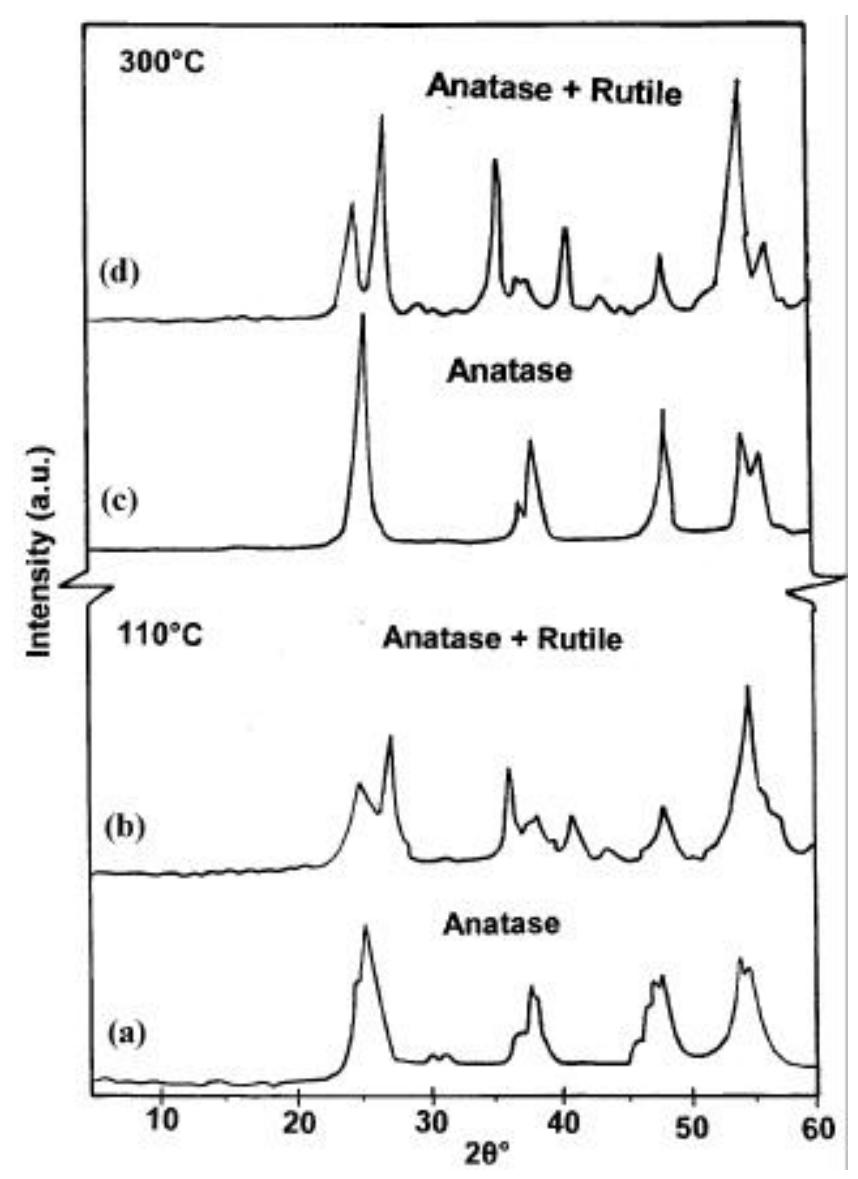

Figure 1. XRD patterns of anatase phase and anatase + rutile mixture prepared by microwave heating to $110^{\circ} \mathrm{C}$ and $300^{\circ} \mathrm{C}$ of $\mathrm{Ti}(\mathrm{OH})_{4}$ precursor obtained by urea precipitation and hydrolysis method, respectively for $60 \mathrm{~min}$. 
size derived from $\mathrm{X}$-ray diffraction data. The crystallite size of anatase increased from $45 \AA$ at $110^{\circ} \mathrm{C}$ to $118 \AA$ at $300^{\circ} \mathrm{C}$ (table 1 ).

The photochemical reactivity of anatase phase and the mixture of anatase and rutile phases prepared by heating their precursors at $110^{\circ} \mathrm{C}$ and $300^{\circ} \mathrm{C}$, respectively are compared in figures 4 and 5 . The decrease in the reactivity of the mixture heat treated at $300^{\circ} \mathrm{C}$ (figure 5) could be attributed more to the increase in rutile content of the mixture $\left(67 \%\right.$ compared to $60 \%$ at $\left.110^{\circ} \mathrm{C}\right)$, which is considered to be less reactive than the anatase phase (Karakitsou and Verykios 1993; Mihaylov et al 1993; Mills et al 1993a, b; Noda et al 1993; Ohtani and Nishimoto 1993; Martin et al 1994). If mean crystallite size was the only factor controlling the reactivity of the sample, then on the basis of the increased mean crystallite size of the anatase as well as the rutile component in the mixture (table 1), the mixture also should exhibit higher reactivity at higher temperature. The decrease in reactivity of the mixture with increasing temperature could thus be understood more on the basis of the decreased surface area and increased rutile content in the sample prepared at high temperature.

One of the interesting features of this investigation is the parabolic dependence of the amount of $\mathrm{Ce}^{4+}$ converted on time (figure 6), suggesting that some kind of diffusion controlled process is involved in the reduction process. The parabolic nature of the plot was independent of whether the $\mathrm{TiO}_{2}$ sample was monophasic (anatase) or biphasic (anatase + rutile mixture). The possibility of such diffusion controlled bimolecular photochemical reaction has been documented (Rohatg-Mukherjee 1992). However, due to limited data it is not possible at this stage to propose any detailed mechanism for the process.

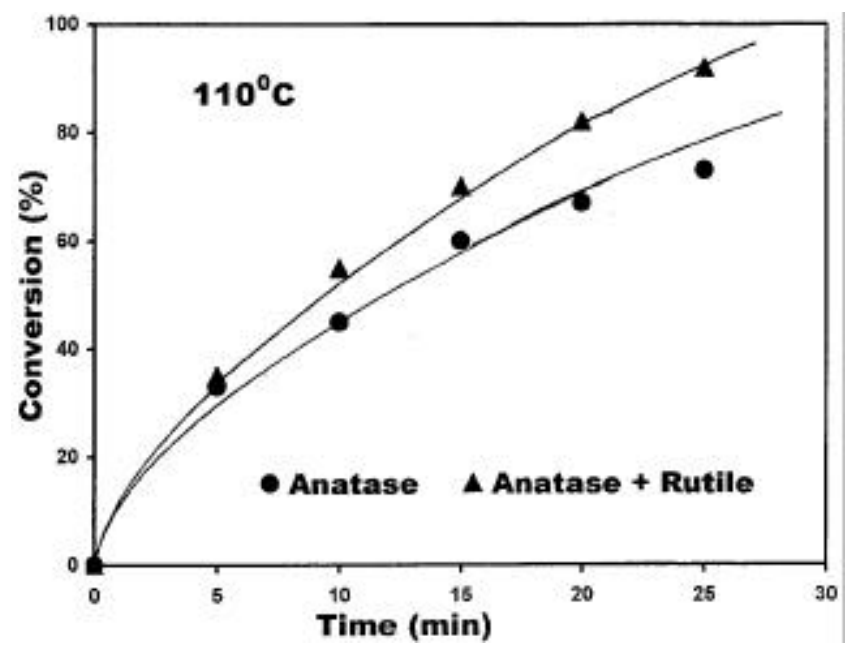

Figure 2. Plot of percentage conversion of $\mathrm{Ce}^{4+}$ to $\mathrm{Ce}^{3+}$ as a function of time $(\mathrm{min})$ for the anatase phase and anatase + rutile mixture prepared by microwave heating at $110^{\circ} \mathrm{C}$ for $60 \mathrm{~min}$.

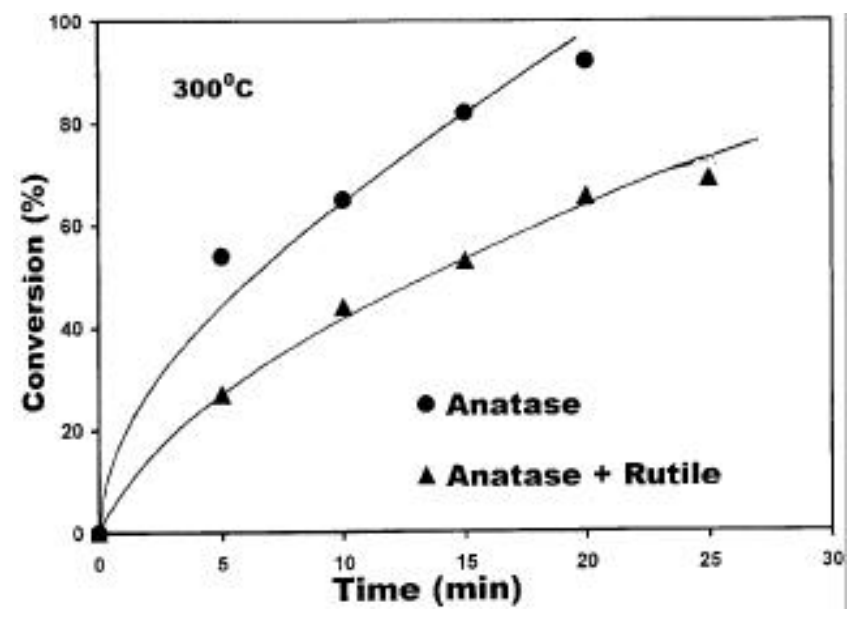

Figure 3. Plot of percentage conversion of $\mathrm{Ce}^{4+}$ to $\mathrm{Ce}^{3+}$ as a function of time ( $\mathrm{min}$ ) for the anatase phase and anatase + rutile mixture prepared by microwave heating at $300^{\circ} \mathrm{C}$ for $60 \mathrm{~min}$.

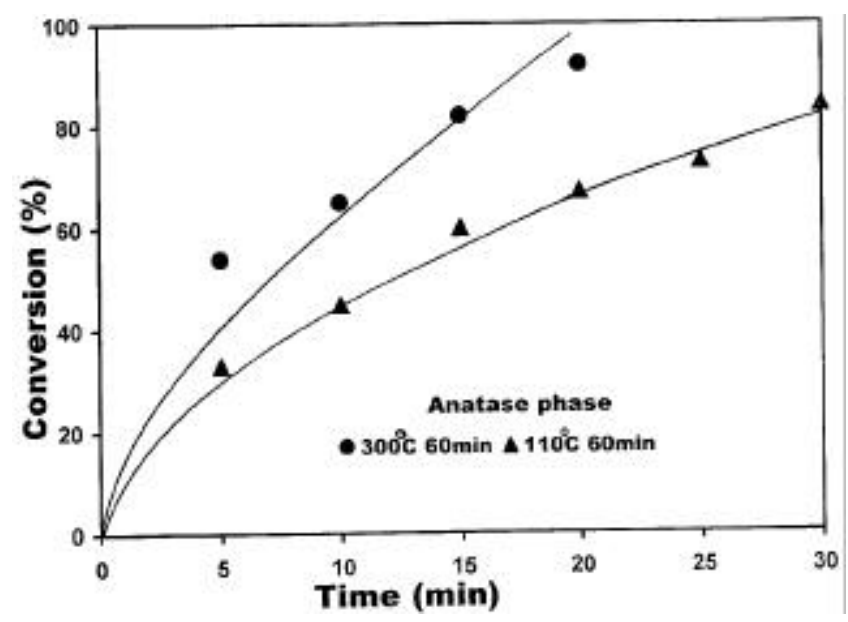

Figure 4. Plot of percentage conversion of $\mathrm{Ce}^{4+}$ to $\mathrm{Ce}^{3+}$ as a function of time (min) for the anatase phase prepared by microwave heating at $110^{\circ} \mathrm{C}$ and $300^{\circ} \mathrm{C}$ for $60 \mathrm{~min}$.

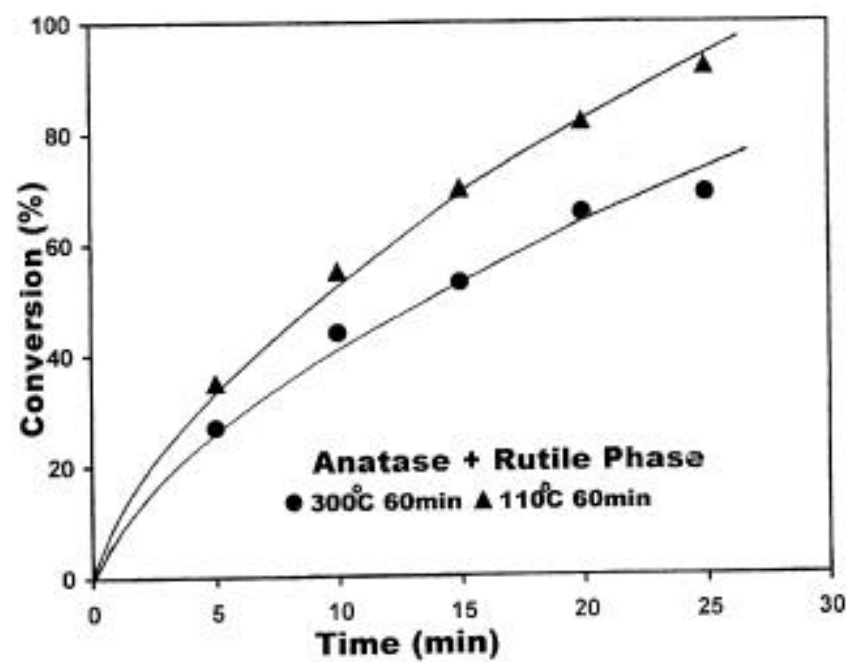

Figure 5. Plot of percentage conversion of $\mathrm{Ce}^{4+}$ to $\mathrm{Ce}^{3+}$ as a function of time $(\mathrm{min})$ for anatase + rutile mixture prepared by microwave heating at $110^{\circ} \mathrm{C}$ and $300^{\circ} \mathrm{C}$, respectively for $60 \mathrm{~min}$. 


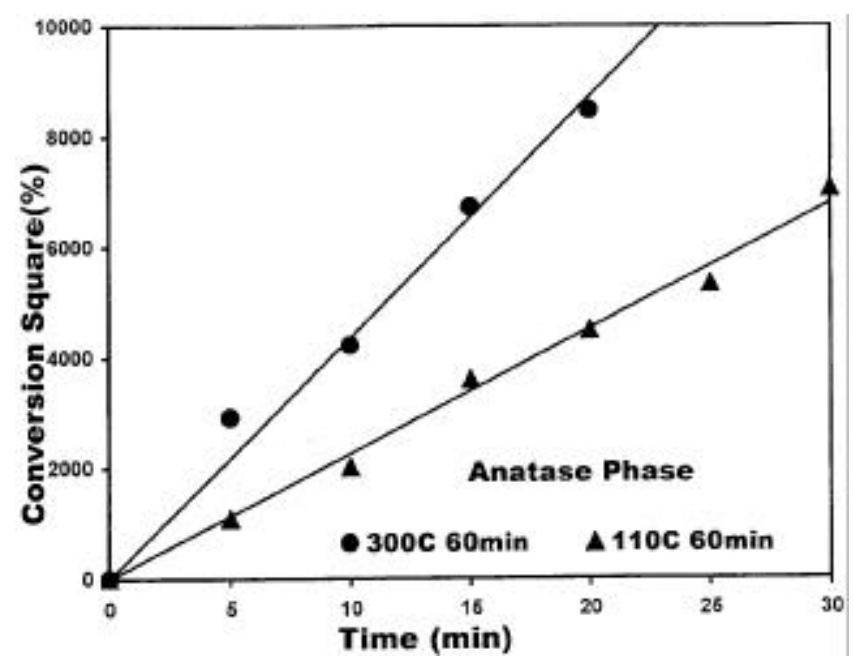

Figure 6. Plot of conversion square of $\mathrm{Ce}^{4+}$ to $\mathrm{Ce}^{3+}$ as a function of time $(\mathrm{min})$ for the anatase phase prepared by microwave heating at $110^{\circ} \mathrm{C}$ and $300^{\circ} \mathrm{C}$ for $60 \mathrm{~min}$.

\section{Conclusions}

The results of this investigation suggest that it is possible to study photocatalytic activity of $\mathrm{TiO}_{2}$ catalysts in presence of sunlight using simple red-ox titration technique. The study also reveals that the reactivity of the mixture of anatase and rutile phases prepared via hydrolysis route is relatively higher compared to that of anatase phase prepared under identical condition when the temperature of heat treatment of the hydroxide precursor is relatively low (i.e. $110^{\circ} \mathrm{C}$ ). The sintering of anatase and rutile mixture with increasing temperature results in the reduction of its reactivity, probably due to decrease in mean surface area and increase in its rutile content with increasing temperature. Anatase also sinters with increasing temperature, but its continuous conversion to rutile simultaneously could result initially, in the creation of an interface between anatase and rutile phases, which could probably be catalytically more reactive. Such enhanced reactivity at the point of phase transitions in the materials has been a common phenomena in solid state reactions (Hedvall 1966). This reactivity can, however, decrease when the
$\mathrm{TiO}_{2}$ in the anatase form transforms to rutile substantially, as it happens above $600^{\circ} \mathrm{C}$.

\section{References}

Cullity B D 1967 Elements of X-ray diffraction (USA: AddisonWesley Publishing Company Inc.)

Dube G R and Darshane V S 1993 J. Mol. Catal. 79285

Fox M A and Dulay M T 1993 Chem. Rev. 93341

Fujishima A, Rao T N and Tryk D A 2000 J. Photochem. and Photobiol. C: Photochem. Rev. 11

Hagfeldt A and Gratzel M 1995 Chem. Rev. 9549

Hedvall J A 1966 Solid state chemistry (Amsterdam: Elsevier Scientific Publication)

Hoffmann M A, Martin S T, Choi W and Bahnemann D W 1995 Chem. Rev. 9569

Karakitsou K E and Verykios X E 1993 J. Phys. Chem. 971184

Linsebigler A L, Lu G and Yates J T 1995 Chem. Rev. 95735

Martin S T, Morrison C L and Hoffmann M R 1994 J. Phys. Chem. 9813695

Mihaylov B V, Hendrix J L and Nelson J H 1993 J. Photochem. Photobiol. A: Chem. 72173

Mills A and Morris S 1993 J. Photochem. Photobiol. A: Chem. 71285

Mills A, Morris S and Davis R 1993a J. Photochem. Photobiol. A: Chem. 70183

Mills A, Davis R H and Worsley D 1993b Chem. Soc. Rev. 22417

Murugesan V 2001 Proceedings on workshop on catalysis on sustainable development through catalysis (Mumbai: Catalyst Society of India) p. 17

Nishimoto S, Ohtani B, Kajiwara H and Kagiya T 1985 J. Chem. Soc., Faraday Trans. 181

Noda H, Oikawa K and Kamada H 1993 Bull. Chem. Soc. Jpn $\mathbf{6 6} 445$

Ohtani B and Nishimoto S 1993 J. Phys. Chem. 97920

Okamoto Ken-ichi and Yasunori Yamamoto 1985 Bull. Chem. Soc. Jpn $\mathbf{5 8} 2015$

Prairie Michael R, Evans Lindsey R, Stange Bertha M and Martinez Sheryl L 1993 Environ. Sci. Technol. 271176

Rajeshwar K 1996 Chem. \& Ind. 1214

Rohatg-Mukherjee K K 1992 Fundamentals of photochemistry (Delhi: Wiley Eastern Publ.)

Tanaka K, Hisanaga T and Rivera A P 1993 in Photocatalytic purification and treatment of water and air (eds) H Al Ekabi and D F Olis (Amsterdam: Elsevier) p. 337

Zhang H and Banfield J F 2000 J. Mater. Res. 15437 